\title{
Predictors of hope among women with breast cancer during chemotherapy*
}

\author{
Fatores preditores da esperança entre mulheres com câncer \\ de mama durante o tratamento quimioterápico \\ Factores predictivos de la esperanza entre mujeres con cáncer \\ de mama durante el tratamiento quimioterápico
}

\author{
Alessandra Cristina Sartore Balsanelli ${ }^{1}$, Sonia Aurora Alves Grossi ${ }^{1}$
}

\section{How to cite this article:}

Balsanelli ACS, Grossi SAA. Predictors of hope among women with breast cancer during chemotherapy. Rev Esc Enferm USP. 2016;50(6):898-904. DOI: http:// dx.doi.org/10.1590/S0080-623420160000700004

\begin{abstract}
* Extracted from the dissertation "Fatores preditores da esperança em pacientes com câncer de mama em tratamento quimioterápico”, Escola de Enfermagem, Universidade de São Paulo, 2012.

${ }^{1}$ Universidade de São Paulo, Escola de Enfermagem, Departamento de Enfermagem Médico-Cirúrgica, São Paulo, SP, Brazil.
\end{abstract}

\begin{abstract}
Objective: Identifying the predictors of hope in patients with breast cancer during chemotherapy treatment. Method: A prospective longitudinal study. The sample was composed of 122 women who responded to the instruments of hope, anxiety and depression, coping, fatigue, religiosity and self-esteem in the first and last cycle of chemotherapy. These variables were used in adjusting the logistic regression model that characterized multivariate statistics, allowing identification of predictor variables. Result: The increase of hope at the end of chemotherapy treatment was statistically significant $(p=0.012)$. The delay in undergoing treatment from the onset of breast cancer symptoms, Karnofsky Performance Status, depression, self-esteem and pain were characterized as factors being associated to hope by univariate analysis. Among the variables analyzed, pain was the only predicting factor of hope. Conclusion: Pain was the predicting factor in this sample. Hope increased during treatment and revealed the following associated factors: Karnofsky Performance Status, delay in starting the treatment, depression, selfesteem and pain. This study brought forth a multidisciplinary contribution, allowing for understanding the factors that can influence hope and presenting support to nursing care. The data evidenced conditions of improvement or worsening of hope, which requires interdisciplinary attention in Oncology.
\end{abstract}

\section{DESCRIPTORS}

Breast Neoplasms; Drug Therapy; Hope; Pain; Oncology Nursing; Reproducibility of Results.
Corresponding author:

Alessandra Cristina Sartore Balsanelli

Rua Loefgreen, 1654, apto. 91 - Vila Clementino

CEP 04040-002 - São Paulo, SP, Brazil

alessandrasartore@hotmail.com
Received: 01/14/2016

Approved: 10/25/2016 


\section{INTRODUCTION}

The diagnosis of cancer arouses innumerable feelings and emotions, among them, hope. This feeling can be seen as a resource that helps patients in coping with psychological suffering associated to the disease $\mathrm{e}^{(1-3)}$.

In the medical field, all definitions of hope involve something that is desired in the future, and when it is associated to the present it can have a positive influence on well-being or, at least, reflect in a positive state ${ }^{(2)}$.

Having hope is essential after a cancer diagnosis is disclosed, since the news can cause suffering and is usually received as a threat. The patient often believes that the diagnosis of cancer is a death sentence, probably resulting in a profound loss of hope, leading to deleterious consequences to their prognosis ${ }^{(4)}$. Maintaining hope enables incurable cancer patients to accept treatment or clinical research, even if there are few benefits ${ }^{(2)}$.

The study of this construct has aroused interest, as it seems to be directly related to the success of cancer treatments and management of signs and symptoms ${ }^{(5-6)}$. Hope presents some strategies that facilitate the daily practice of nursing. It is made feasible by human principles which are the basis of care, by the use of knowledge put into practice, by interpersonal relationships, and how health professionals handle the environment and care organization ${ }^{(7)}$.

Nurses are an important source of hope for people who are vulnerable and ill, as they are in constant contact with those who are suffering ${ }^{(7)}$. This is particularly true for oncologic patients who, due to their long stay in the hospital environment and the repeated returns established by the treatment protocols, maintain close contact with nurses, in addition to the affective bond created.

Some variables frequently associated to hope have been identified by scientific studies, and understanding them can influence the quality of care. Regarding this, there is religiosity, a factor that is usually evaluated in the spiritual domain of the instruments that evaluate quality of life as being possibly weakened by a cancer diagnosis, and may lead the patient to contemplate their own mortality and often poses unique challenges to their beliefs ${ }^{(4,8)}$.

Other associated variables may include:

Fatigue: The cancer patient often presents a fatigue symptom, whether it is due to illness or to treatment ${ }^{(2,9)}$.

Karnofsky Performance Status (KPS): The functional clinical condition of the cancer patient is usually assessed by assessment scales, such as KPS, being necessary for clinical decisionmaking. It was found that low KPS scores, which indicate low functionality, are related to a lower index of hope ${ }^{(1)}$.

Coping: Literature associates hope as an important resource and coping mechanism ${ }^{(1)}$.

Anxiety and depression: Hope and optimism are negatively correlated to anxiety and depression ${ }^{(10-11)}$. The higher the hope scores, the lower the possibility of the patient presenting a score of depression ${ }^{(5-6)}$.

Hope and self-esteem:self-esteem in patients with breast cancer, from the discovery of the disease and during treatment is subject to change, constituting an important object of study ${ }^{(5,12)}$. Despite the physical and psychological changes suffered by these patients, they present high self-esteem ${ }^{(12)}$.

It is important to identify the factors that influence hope. Anxiety, depression, fatigue and pain negatively affect the hope ${ }^{(11)}$.

The present study investigates which other variables can be associated to or be predictors of hope in patients with breast cancer during chemotherapy treatment. The interest in the topic as well as the small number of studies that investigate such factors have fostered the development of the present study, aiming to identify predictors of hope in patients with breast cancer during chemotherapy treatment.

\section{METHOD}

This is a prospective longitudinal study conducted at a public hospital, which is a reference center for Women's Health, in the city of São Paulo, SP, Brazil.

The inclusion criteria for the sample composition were: patients with breast cancer at clinical stage I, II and III ${ }^{(13)}$; being more than 18 years of age; aware of their diagnosis; in the first chemotherapy treatment; and able to read and respond to the questionnaires.

Patients with metastatic disease and those who did not complete treatment at the chemotherapy outpatient center referenced above were excluded from the study.

The study participants were previously selected from appointments and medical records in the Chemotherapy Outpatient Clinic.

The patients were approached by the principal investigator in the first cycle of chemotherapy and the objectives and benefits of the study in question were clarified, allowing them to express their desire to participate. Those interested in participating signed the Free and Informed Consent Form. They were guided regarding the need to respond to all the questionnaires necessary to achieve the objectives of the study in the proposed first cycle of chemotherapy, characterizing zero time (T0). The same questionnaires were completed again in the last cycle of chemotherapy, which characterized the final time (T1).

Data collection was carried out from March 2011 to March 2012.

An instrument created by the researchers of this study was used to obtain sociodemographic data (age, gender, marital status, education, religion, current occupation and family income) and clinical data (onset of symptoms, date of diagnosis, staging, current treatment, chemotherapy protocol, previous treatments, comorbidities and pain). Information regarding disease stage, other treatments and chemotherapy protocol were obtained through active medical record consultation.

The dependent variable in this study was the evaluation of hope, and was performed using the Herth Hope Index (HHI), culturally adapted and validated for the Portuguese language. This index makes it possible to measure the hope construct in a final score ranging from 12 to 48 . The index has 12 easy-to-understand items ${ }^{(5)}$. There is no cut-off point, resulting in a high or low score of hope and it has been validated in several countries ${ }^{(3)}$. 
Karnofsky Performance Status (KPS) was used to evaluate the patients' health status. The Karnofsky scale is composed of sentences that portray the functional capacity of an individual, and these are graded from $100 \%$ to $0 \%$, where $100 \%$ represents an individual with no evidence of disease and $0 \%$ is a deceased person. There are no cut-off points, and higher scores indicate better functionality. It is a widely-used instrument in international and national cancer studies and clinics ${ }^{(14)}$.

The Numerical Pain Scale was also used since it allows patients to characterize pain intensity using a numerical value from 0 to $10(0=$ absence of pain and $10=$ worst pain imaginable), where 0 - without pain; 1 - mild pain (1-4); 2 - moderate pain (5-7); 3 - severe pain $(8-10)^{(15)}$.

The Jalowiec Coping Scale had the objective of identifying individual characteristics of strategies for coping with stressors. It consists of 60 statements divided into eight styles of coping, namely: confrontational, evasive, optimistic, fatalistic, emotive, palliative, supportive, and self-reliant. The Jalowiec Coping Scale was validated for the Brazilian older adult population with cognitive impairment, observing good reliability. For the final score, the highest relative score is found, which represents the predominant coping style ${ }^{(16)}$.

The Hospital Anxiety and Depression Scale (HADS) contains 14 multiple-choice questions and it has also been validated for the Portuguese language. It consists of two subscales for anxiety and depression, with seven items each. The overall score for each subscale ranges from 0 to 21 . The recommended cut-off points for both subscales are: HAD - anxiety: no anxiety from 0 to 8 , having anxiety $\geq 9$; HAD - depression: no depression from 0 to 8 , having depression $\geq 9$. It is a scale of easy application and understanding ${ }^{(17)}$.

The Rosenberg Self-Esteem Scale (RSES) assessed the self-esteem of patients in this study. It is a scale composed of 10 affirmations with a score of 0 to 3 . The higher the score, the lower the self-esteem. The Portuguese version of this scale presented good reproducibility and validity indexes with patients who were to undergo plastic surgery ${ }^{(18)}$.

The Duke Religion Index (DUREL) has five items that capture three of the dimensions of religiosity that are most related to health outcomes: Organizational religiosity (OR) - first question; Non-organizational religion (NOR) - second question; Intrinsic Religiosity (IR) - grouping of the last three questions. The version adapted for Portuguese is available for use, however the authors suggest that validity and reliability studies of this version are carried out in the Brazilian population. In order to obtain the final score, the number corresponding to the response is associated to the result in that dimension, but with an inverted score, meaning that higher scores represent less religiosity ${ }^{(19)}$.

An assessment of fatigue was performed using the Fatigue Pictogram, an instrument validated for Brazilian culture. The Pictogram is a scale composed of two questions graded in five subtitled illustrations that evaluate the intensity and impact of fatigue. There is no cut-off point for diagnosis or classification of fatigue intensity. Each item was evaluated separately for the psychometric properties test ${ }^{(20)}$.

The predictor factor was revealed through multiple regression which used independent variables to predict the dependent variable of hope. Regression analysis determines values for each independent variable. The weighting of each independent variable reveals its contribution for global prediction and assists in understanding each variable in the prediction ${ }^{(21)}$.

The project was approved by the Research Ethics Committee of the Universidade de São Paulo Escola de Enfermagem, CEP EEUSP (Process no 976/2010), and of the Reference Center for Women's Health (Protocol $\left.n^{\circ} 034 / 10\right)$.

\section{RESULTS}

The convenience sample from the chemotherapy schedule was initially composed of 165 individuals who met the inclusion criteria. The subjects were all interviewed and responded to the intended instruments at the first chemotherapy session. One hundred and twenty-two (122) women concluded the study, being those who responded again to the questionnaires at the end of the chemotherapy treatment. Losses occurred due to metastatic disease in 18 (11\%) of the subjects as confirmed in medical records after the first interview, 2 (1\%) due to deaths, and $23(14 \%)$ due to changes in schedules.

The patients had a mean age of 50 years $(\mathrm{SD}=10.6)$, most of them were married and Catholic. Study participants had median schooling of 8.5 years. Regarding monthly family income, the sample obtained a median of $\mathrm{R} \$ 1,200.00$ (BRL).

The onset of breast cancer symptoms showed a median of 8 months, with a minimum of 3 months and a maximum of 46 months. The time between the diagnosis and the beginning of the treatment showed a median of 4 months, a minimum of 1 month and maximum of 13 months.

The main chemotherapeutic protocols used in this sample were: AC/T-Adriamycin and Cyclophosphamide/ $\operatorname{Taxol}^{\oplus}$ (39.5\%) adjuvant post-operative breast surgery, four cycles of Adriamycin $\left(60 \mathrm{mg} / \mathrm{m}^{2}\right)$ and Cyclophosphamide $\left(600 \mathrm{mg} / \mathrm{m}^{2}\right)$, followed by four cycles of Taxol ${ }^{\circledR}\left(175 \mathrm{mg} / \mathrm{m}^{2}\right)$ every 21 days; FAC - Fluorouracil (5-FU), Adriamycin and Cyclophosphamide (16.5\%), six cycles of Fluorouracil (5-FU) $\left(500 \mathrm{mg} / \mathrm{m}^{2}\right)$, Adriamycin $\left(50 \mathrm{mg} / \mathrm{m}^{2}\right)$ and Cyclophosphamide $\left(600 \mathrm{mg} / \mathrm{m}^{2}\right)$ every 21 days; and the Multicentric Research Protocol (12\%), in which Docetaxel $\left(75 \mathrm{mg} / \mathrm{m}^{2}\right)$, Adriamycin $\left(50 \mathrm{mg} / \mathrm{m}^{2}\right)$ and Cyclophosphamide $\left(500 \mathrm{mg} / \mathrm{m}^{2}\right)$ were used for six cycles every 21 days. The mean duration of chemotherapy treatment between T0 and T1 was 4.2 months.

Surgical treatment (mastectomy or quadrantectomy) was performed in 77 patients (63\%) prior to chemotherapy.

The variation of the scores obtained by applying the Herth Hope Index (HHI) in the studied sample obtained the following values: median of 43 at $\mathrm{T} 0$, and median of 45 at T1. This increase at the end of the chemotherapy treatment was statistically significant $(p=0.012)$.

As the Herth Hope Index does not have a cut-off point, it was necessary to divide the sample into two groups; one for which the hope score during treatment was maintained or increased, and another in which it decreased. There was a decrease in the HHI score in $35 \%$ of the sample. All analyzes to identify predictors were made considering the categorized hope variation (decreased or maintained/increased) 
at moments $\mathrm{T} 0$ and $\mathrm{T} 1$. These analyzes characterize the univariate statistics, which enabled studying of variables associated to hope.

The delay in starting treatment for patients since the onset of breast cancer symptoms showed a median time of 8 months. The patients who took longer to start chemotherapy showed a significant decrease in hope scores over the same period $(p=0.013)$. Univariate analysis characterizes this variable as a factor associated to hope.

The group with decreased hope scores presented lower KPS values at time T1. This decrease was statistically significant $(p=0.02)$. Univariate analysis characterizes this variable as a factor associated to hope.

An assessment of anxiety and depression was carried out and associated to the variation of hope between $\mathrm{T} 0$ and $\mathrm{T} 1$. The association is shown in Table 1.

Table 1 - Association between the variation of Hope, Anxiety and Depression at time zero and final time - São Paulo, SP, Brazil, 2012.

\begin{tabular}{|c|c|c|c|c|c|}
\hline Variable & $\begin{array}{l}\text { HHI Score } \\
\text { (T1-T0) }\end{array}$ & Median & $\begin{array}{c}\text { Int } \\
\text { rang } \\
3 \mathrm{rc}\end{array}$ & $\begin{array}{l}\text { artile } \\
\text { t and } \\
\text { rtile) }\end{array}$ & $p$ \\
\hline \multirow{2}{*}{$\begin{array}{l}\text { HADS Score } \\
\text { A }^{*} \text { TO }\end{array}$} & $\begin{array}{l}\text { Maintained/ } \\
\text { Increased }\end{array}$ & 6 & 3 & 10 & \multirow{2}{*}{0.721} \\
\hline & Decreased & 6 & 4 & 8 & \\
\hline \multirow{2}{*}{$\begin{array}{l}\text { HADS Score } \\
\text { A T1 }\end{array}$} & $\begin{array}{l}\text { Maintained/ } \\
\text { Increased }\end{array}$ & 4 & 2 & 7 & \multirow[t]{2}{*}{0.087} \\
\hline & Decreased & 5 & 3 & 9 & \\
\hline \multirow{2}{*}{$\begin{array}{l}\text { HADS Score } \\
D^{+} T 0\end{array}$} & $\begin{array}{l}\text { Maintained/ } \\
\text { Increased }\end{array}$ & 4 & 2 & 6 & \multirow[t]{2}{*}{0.645} \\
\hline & Decreased & 5 & 3 & 6 & \\
\hline \multirow{2}{*}{$\begin{array}{l}\text { HADS Score } \\
\text { D T1 }\end{array}$} & $\begin{array}{l}\text { Maintained/ } \\
\text { Increased }\end{array}$ & 3 & 1 & 5 & \multirow[t]{2}{*}{0.004} \\
\hline & Decreased & 5 & 3 & 8 & \\
\hline
\end{tabular}

*Score A: Anxiety Score, ${ }^{\dagger}$ Score D: Depression Score.

The group whose hope decreased during the treatment presented a significant increase in depression scores $(p=0.004)$. Univariate analysis characterizes this variable as a factor associated to hope.

The results of the association between variation of hope during treatment and self-esteem are demonstrated in Table 2.

Table 2 - Association between variation of Hope and Self-esteem at time zero and final time - São Paulo, SP, Brazil, 2012.

\begin{tabular}{llcccc}
\hline Variable & $\begin{array}{c}\text { HHI Score } \\
\text { (T1-T0) }\end{array}$ & Median & $\begin{array}{c}\text { Interquartile } \\
\text { range (1st and 3rd } \\
\text { quartile) }\end{array}$ & $\boldsymbol{p}$ \\
\hline $\begin{array}{l}\text { RSES } \\
\text { Score T0 }\end{array}$ & $\begin{array}{l}\text { Maintained/ } \\
\text { Increased } \\
\text { Decreased }\end{array}$ & 8 & 3 & 11 & 0.060 \\
RSES & $\begin{array}{l}\text { Maintained/ } \\
\text { Increased }\end{array}$ & 3 & 2 & 7 & 0.001 \\
Score T1 & $\begin{array}{l}\text { Decreased } \\
\text { Decrease }\end{array}$ & 7 & 3 & 10 & \\
\hline
\end{tabular}

*RSES: Rosenberg Self-Esteem Scale.

These results demonstrate that the group that had decreased hope between $\mathrm{T} 0$ and $\mathrm{T} 1$ had higher self-esteem scores at $\mathrm{T} 1(p=0.001)$. The RSES score is inverted, meaning that the patients who had decreased hope had lower selfesteem. Univariate analysis characterizes this variable as a factor associated to hope.

The investigation of pain at the beginning and at the end of treatment associated to the variation of hope is represented in Table 3.

Table 3 - Association between the variation of Hope and Pain at time zero and final time - São Paulo, SP, Brazil, 2012.

\begin{tabular}{llcccc}
\hline Variable & $\begin{array}{c}\text { HHI Score } \\
\text { (T1-T0) }\end{array}$ & Median & $\begin{array}{c}\text { Interquartile } \\
\text { range (1st and 3rd } \\
\text { quartile) }\end{array}$ & $\boldsymbol{p}$ \\
\hline Pain T0 & $\begin{array}{l}\text { Maintained/ } \\
\text { Increased } \\
\text { Decreased }\end{array}$ & 0 & 0 & 5 & 0.034 \\
Pain T1 & $\begin{array}{l}\text { Maintained/ } \\
\text { Increased }\end{array}$ & 0 & 0 & 3 & 0.641 \\
\hline & Decreased & 0 & 0 & 5 & \\
\hline
\end{tabular}

Patients who reported pain at T0 had their hope score decreased at the end of treatment. This decrease was statistically significant $(p=0.034)$. Univariate analysis characterizes this variable as a factor associated to hope.

The variables that presented statistical significance in the univariate analysis were used to adjust the logistic regression model. This model characterized the multivariate statistics, allowing for identifying predictors of hope.

Pain was the only tested variable predictive of hope in the sample studied.

Multivariate analysis using the odds ratio identifies pain as a predictor of decreased hope. If the patient reports pain, the chance of the HHI score decreasing is 2.199 times greater than in a patient who does not report pain $(p=0.042)$.

The variables religiosity, fatigue and coping did not present significant alterations with variation of the hope score.

\section{DISCUSSION}

This longitudinal study investigated hope and its predictive factors in 122 breast cancer patients undergoing chemotherapy at the beginning and at the end of treatment.

Patients in this study had a median HHI score of 43 at $\mathrm{T} 0$ and 45 at T1, which represents a high level of hope since the score ranges from 12 to 48 . Results similar to the present study were found in the HHI validation study for the Portuguese language, in which a mean score of 41.57 was found for cancer patients, 40.46 for diabetic patients and 40.88 for the companions of these patients ${ }^{(5)}$.

Chinese women with breast cancer undergoing chemotherapy had a high hope score, with a total score of $38.62 \pm$ 4.56. There was no statistical difference between hope and age, educational level, marital status, work condition or cancer stage, however there was statistical difference between hope and monthly income; the higher the monthly income, the greater the hope ${ }^{(22)}$.

Another study which aimed to describe hope in oncologic patients with pain $(n=225)$, and to determine which variables were related to hope, concluded that hospitalized 
cancer patients with pain had higher hope than the population of Norway. However, the patients reported lower scores for the item "I'm afraid of my future" on the $\mathrm{HHI}^{(23)}$.

A Japanese study comparing the symptoms of suffering and reaching a good death among older adult and young patients with cancer identified the loss of hope and pleasure in older adult patients with metastatic cancer ${ }^{(24)}$.

The time interval between the perception of breast cancer symptoms and the beginning of treatment had a median of 8 months; this is a long period considering the need to establish treatment as early as possible. This time interval was a factor associated to hope in this study. Patients who took longer to start chemotherapy treatment had a significant decrease in their hope scores throughout the treatment. A Brazilian study showed that the longest delay in the conduct of breast cancer cases occurred between the mammography and biopsy of suspicious lesions. The greatest delay in diagnosis was related to more advanced stages of the disease. The interval between a suspicious mammography and the onset of systemic therapy ( $>180$ days) stands out, since this is the time interval in which potential micrometastases can take place, leading the disease to become metastatic and generally incurable ${ }^{(25)}$.

The patients in this study presented an increase in the Karnofsky Performance Status at the end of treatment when compared to the beginning. The median KPS in these patients was 90 at $\mathrm{T} 0$ and $\mathrm{T} 1$, which means that the patients were able to lead a normal life even when dealing with minor signs or symptoms of the disease. KPS was found to be a factor associated to hope in this study. The median of 90 is a high value of KPS when compared to that of cancer patients with pain from a Norwegian study, which obtained an average of $64.9 \%( \pm 15.6)^{(23)}$.

Anxiety and depression have been identified as common psychological distress factors in most cancer patients ${ }^{(10)}$. The group that had decreased hope presented an increase in the depression score, which favors evaluating hope as a positive way in coping with the disease ${ }^{(1)}$. Depression in this sample was a factor associated to hope. An American study investigating hope and suffering symptoms found that depression was the only inversely significant variable in the multivariate analysis. The other variables (pain, activity, nausea, depression, feeling sad, feeling nervous, anxiety, drowsiness, appetite, well-being and dyspnea) had a weak correlation with hope ${ }^{(11)}$.

The patients in this study showed increased self-esteem at the end of the chemotherapy treatment. In cancer patients, self-esteem showed a positive correlation with hope, meaning that the higher the self-esteem score, the higher the hope score $^{(5)}$. Statistical analysis revealed self-esteem as a factor associated to hope.
Breast pain was present in 54 patients at the start of treatment, making up $44 \%$ of the sample. At the end of the treatment, 47 patients (38.5\%) complained of pain. This information is similar to a study conducted to investigate the prevalence and comorbidity of pain and fatigue in women with breast cancer in which $47 \%$ of the patients presented pain $^{(26)}$. Pain imposes many limits on the lifestyle of the patient who suffers from it. Immobility and impatience are some of the outcomes of disease progression. The concept of total pain consisting of the physical, mental, social, and spiritual components reveals that pain relief is not achieved if all of these areas are neglected. Sensitive, emotional and cultural aspects are inseparable in pain and should also be evaluated ${ }^{(26)}$.

The main result of this study narrowed the concepts of pain and hope. In this sample, pain was an associated factor and the only predictor of hope. This is noticeable in clinical practice; however, there is a need for more research that investigates the topic. New studies can be carried out with different samples.

For nursing, this result represents collaboration in improving care for cancer patients with pain. A disorder caused by pain requires interdisciplinary assistance, in addition to evaluation, pharmacological and non-pharmacological therapy. Longitudinal studies with interventions that increase hope and involve its associated factors and predictors constitute a vast field to be explored in future research.

This study had the decrease in the number of patients from $\mathrm{T} 0$ to $\mathrm{T} 1$ as a limitation. This loss occurred due to metastatic disease reported in the medical records after starting treatment. There were also changes in dates in scheduling patients (without previous information), and deaths reported by relatives via telephone call.

\section{CONCLUSION}

The results of this study allow us to conclude that the hope in women with breast cancer undergoing chemotherapy treatment who composed the sample were positively evaluated at the beginning of the chemotherapy and improved significantly at the end of it.

Patients who reported pain at the start of treatment had a decreased hope score at the end of treatment $(p=0.034)$. Among the analyzed variables, pain was the only predictor of hope. The presence of pain may decrease hope by 2.199 times more than in patients who do not report having pain.

This study significantly contributes to the knowledge for clinical practice of cancer patients, since it presents unprecedented results that allow us to understand the factors associated to hope, as well as its predictive factor and to implement improvement in the care of these patients.

Objetivo: Identificar os fatores preditores da esperança nas pacientes com câncer de mama em tratamento quimioterápico. Método: Estudo prospectivo longitudinal. A amostra foi de 122 mulheres que responderam aos instrumentos de esperança, ansiedade e depressão, coping, fadiga, religiosidade e autoestima no primeiro e no último ciclo de quimioterapia. Essas variáveis foram utilizadas no ajuste do modelo de regressão logística que caracterizou a estatística multivariada permitindo a identificação das variáveis preditoras. 
Resultado: O aumento da esperança ao final do tratamento quimioterápico foi estatisticamente significante $(p=0,012)$. A demora na realização do tratamento desde o início dos sintomas do câncer de mama, o Karnofsky Performance Status, a depressão, a autoestima e a dor foram caracterizadas como fatores associados à esperança pela análise univariada. Dentre as variáveis analisadas, a dor apresentouse como o único fator preditor da esperança. Conclusão: A dor foi o fator preditor nesta amostra. A esperança aumentou durante o tratamento e revelou os fatores associados: Karnofsky Performance Status, demora no início do tratamento, depressão, autoestima e dor. Este estudo trouxe uma contribuição multidisciplinar, permitiu compreender os fatores que podem influenciar a esperança e apresentou subsídios à assistência de enfermagem. Os dados evidenciaram condições de melhora ou agravamento da esperança, o que requer atenção interdisciplinar em Oncologia.

\section{DESCRITORES}

Neoplasias da Mama; Quimioterapia; Esperança; Dor; Enfermagem Oncológica; Reprodutibilidade dos Testes.

\section{RESUMEN}

Objetivo: identificar los factores predictivos de la esperanza en las pacientes con cáncer de mama en tratamiento quimioterápico. Método: Estudio prospectivo longitudinal. La muestra fue de 122 mujeres que respondieron a los instrumentos de esperanza, ansiedad y depresión, coping (enfrentamiento), fatiga, religiosidad y autoestima el primero y el último ciclo de quimioterapia. Dichas variables fueron utilizadas en el ajuste del modelo de regresión logística que caracterizó la estadística multivariada permitiendo la identificación de las variables predictivas. Resultado: El aumento de la esperanza al final del tratamiento quimioterápico fue estadísticamente significativo $(p=0,012)$. La demora en la realización del tratamiento desde el inicio de los síntomas del cáncer de mama o Karnofsky Performance Status, la depresión, la autoestima y el dolor se caracterizaron como factores asociados con la esperanza por el análisis univariado. Entre las variables analizadas, el dolor se presentó como el único factor predictor de la esperanza. Conclusión: El dolor fue el factor predictor en esta muestra. La esperanza aumentó durante el tratamiento y reveló los factores asociados: Karnofsky Performance Status, demora en el inicio del tratamiento, depresión, autoestima y dolor. Este estudio brindó un aporte multidisciplinario, permitió comprender los factores que pueden influenciar la esperanza y presentó subsidios para la asistencia de enfermería. Los datos evidenciaron condiciones de mejora o agravamiento de la esperanza, lo que requiere atención interdisciplinaria en Oncología.

\section{DESCRIPTORES}

Neoplasias de la Mama; Quimioterapia; Esperanza; Dolor; Enfermería Oncológica; Reproducibilidad de Resultados.

\section{REFERENCES}

1. Rustoen T, Cooper BA, Miaskowski C. The importance of hope as a mediator of psychological distress and life satisfaction in a community sample of cancer patients. Cancer Nurs. 2010;33(4):258-67.

2. Olver IN. Evolving definitions of hope in oncology. Curr Opin Support Palliat Care. 2012;6(2):236-41.

3. Chi GC. The role of hope in patients with cancer. Oncol Nurs Forum. 2007;34(2):415-24.

4. Richardson P. Assessment and Implementation of spirituality and religiosity in cancer care: effects on patient outcomes. Clin J Oncol Nur. 2012;16(4):150-5.

5. Sartore AC, Grossi SAA. Escala de Esperança de Herth: instrumento adaptado e validado para a língua portuguesa. Rev Esc Enferm USP. 2008;42(2):227-32.

6. Balsaneli ACS, Grossi SAA, Herth K. Assessment of hope in patients with chronic illness and their family or caregivers. Acta Paul Enferm. 2011;24(3):354-8.

7. Tabrizi FM, Radfar M, Taei Z. Effects of supportive-expressive discussion groups on loneliness, hope and quality of life in breast cancer survivors: a randomized control trial. Psychooncology. 2016;25(9):1057-63.

8. Grant M, Sun V. Advances in quality of life at the end of life. Semin Oncol Nurs. 2010;26(1):26-35.

9. Runowicz CD, Leach CR, Henry NL, Henry KS, Mackey HT, Cowens-Alvarado RL. American Cancer Society/American Society of Clinical Oncology Breast Cancer Survivorship Care Guideline. J Clin Oncol. 2016;34(6):611-35.

10. Rajandram RK, Ho SMY, Samman N, Chan N, McGrath C, Zwahlen RA. Interaction of hope and optimism with anxiety and depression in a specific group of cancer survivors: a preliminary study. BMC Res Notes. 2011;28(4):519-25.

11. Davis MP, Lagman R, Parala A, Patel C, Sanford T, Fielding F, et al. Hope, symptoms and palliative care: do symptoms influence hope? Am J Hosp Palliat Care. 2016 Jan 25. pii: 1049909115627772. [Epub ahead of print]

12. Heidari $M$, Ghodusi $M$. The relationship between body esteem and hope and mental health in breast cancer patients after mastectomy. Indian J Palliat Care. 2015;21(2):198-202.

13. Edge SB, Byrd DR, Compton CC, Fritz AG, Greene FL, Trotti A. AJCC cancer staging manual. 7th ed. New York: Springer; 2010.

14. Oken MM, Creech RH, Tormey DC, Horton J, Davis TE, McFadden ET, et al. Toxicity and response criteria of the Eastern Cooperative Oncology Group. Am J Clin Oncol. 1982;5(6):649-55.

15. Sesay M, Robin G, Tauzin-Fin P, Sacko O, Gimbert E, Vignes J, et al. Responses of heart rate variability to acute pain after minor spinal surgery: optimal Thresholds and correlations with the numeric rating scale. J Neurosurg Anesthesiol. 2015;27(2):148-54.

16. Kato T. Frequently used coping scales: a meta-analysis. Stress Health. 2015;31(4):315-23.

17. Marcolino JAM, Mathias LAST, Piccinini Filho L, Guaratini AA, Suzuki FM, Alli LAC. Escala Hospitalar de Ansiedade e Depressão: estudo da validade de critério e da confiabilidade com pacientes no pré-operatório. Rev Bras Anestesiol. 2007;57(1):52-62.

18. Dini GM, Quaresma MR, Ferreira LM. Adaptação cultural e validação da versão brasileira da Escala de Auto-estima de Rosenberg. Rev Soc Bras Cir Plást 2004;19(1):47-52. 
19. Moreira-Almeida A, Peres MF, Aloe F, Lotufo-Neto F, Koenig HG. Versão em português da Escala de Religiosidade da Duke - DUREL. Rev Psiq Clin. 2008;35(1):31-2.

20. Mota DDCF, Pimenta CAM, Fitch MI. Fatigue Pictogram: an option for assessing fatigue severity and impact. Rev Esc Enferm USP [Internet]. 2009 [cited 2015 Nov 16];43(n.esp):1079-86. Available from: http://www.scielo.br/pdf/reeusp/v43nspe/en_a12v43ns.pdf

21. Hair JF, Anderson RE, Tatham RL, Black WC. Multivariate data analysis. 5th ed. New Jersey: Prentice Hall; 1998.

22. Zhang J, Gao W, Wang P, Wu ZH. Relationships among hope, coping style and social support for breast cancer patients. Chin Med J. 2010;123(17):2331-5.

23. Utne I, Miaskowski C, Bjordal K, Paul SM, Jakobsen G, Rustoen T. The relationship between hope and pain in a sample of hospitalized oncology patients. Palliat Support Care. 2008;6(4):327-34.

24. Morita T, Kuriya M, Miyashita M, Sato K, Equchi K, Akechi T. Symptom burden and achievement of good death of elderly cancer patients. J Palliat Med. 2014;17(8):887-93.

25. Trufelli DC, Miranda VC, Santos MBB, Fraile NMP, Pecoroni PG, Gonzaga SFR, et al. Análise do atraso no diagnóstico e tratamento do câncer de mama em um hospital público. Rev Assoc Med Bras. 2008;54(1):72-6.

26. Lamino DA, Mota DDCF, Pimenta CAM. Prevalence and comorbidity of pain and fatigue in women with breast cancer. Rev Esc Enferm USP [Internet]. 2011 [cited 2015 Nov 17];45(2):508-14. Available from: http://www.scielo.br/pdf/reeusp/v45n2/en_v45n2a28.pdf 